Wirtschaftswissenschaftliches Zentrum (WWZ) der Universität Basel

$\mathrm{WW} \mid \mathrm{Z}$

June 2014

\title{
Swissmod - A Model of the Swiss Electricity Market
}


Corresponding Authors:

\section{Ingmar Schlecht}

Forschungsstelle Nachhaltige Energie- und Wasserversorgung

Wirtschaftswissenschaftliche Fakultät der Universität Basel

Peter Merian-Weg 6

Postfach, CH-4002 Basel

Tel. +41 (0)61 2673345

Fax +41 (0)612670496

ingmar.schlecht@unibas.ch

\section{Prof Dr. Hannes Weigt}

Forschungsstelle Nachhaltige Energie- und Wasserversorgung

Wirtschaftswissenschaftliche Fakultät der Universität Basel

Peter Merian-Weg 6

Postfach, CH-4002 Basel

Tel. +41 (0)61 2673259

Fax +41 (0)612670496

hannes.weigt@unibas.ch

A publication of the Center of Business and Economics (WWZ), University of Basel.

(C) WWZ 2014 and the authors. Reproduction for other purposes than the personal use needs the permission of the authors. 


\title{
Swissmod - A Model of the Swiss Electricity Market
}

\author{
Ingmar Schlecht* Hannes Weigt ${ }^{\dagger}$ \\ Universität Basel, Wirtschaftswissenschaftliche Fakultät (WWZ) \\ Forschungsstelle Nachhaltige Energie- und Wasserversorgung $\ddagger$ \\ June 2014
}

\begin{abstract}
We present a bottom-up electricity market model for Switzerland called Swissmod. It includes a detailed electricity network and hydropower representation. Swissmod captures the features and restrictions of run-of-river, yearly storage and pumped-storage power plants and combines this with a network model of the river and water stream system to take the interdependence of hydraulically coupled hydropower plants into account. In addition, the Swiss electricity network is represented using the DC load flow approach, allowing for spatial market evaluations. The model is developed as a deterministic optimization problem in GAMS. It provides an hourly resolution over a one-year horizon with an approximated representation of the surrounding European electricity markets. The aim of this paper is to outline the model and calibrate it to 2012 data.
\end{abstract}

Keywords: Switzerland, electricity markets, power flow, hydropower, nodal pricing.

\footnotetext{
${ }^{*}$ E-mail: ingmar.schlecht@unibas.ch.

${ }^{\dagger}$ E-mail: hannes.weigt@unibas.ch.

${ }^{\ddagger}$ Peter Merian-Weg 6, CH-4002 Basel, Switzerland.
} 


\section{Introduction}

The European energy policy is aiming for a transition from the fossil based current energy system towards a carbon free system based on renewable energy sources. The 20-20-20 targets of reduced emissions, increased renewable share, and increased energy efficiency till 2020 are the next important milestone in this process. Switzerland, not being a member state of the European Union, does not need to follow the same guidelines. Nevertheless, the energy policy goals of Switzerland follow a similar vision of transforming the energy system towards a sustainable path with less fossil fuel consumption and an increased renewable share. The Swiss policy process has experienced a significant shift as a reaction to the nuclear accident in Japan in March 2011. Whereas the existing nuclear plants were planned to be replaced by new plants after their expected life time, the new energy policy program, "Energy Strategy 2050" (BFE 2012a), excludes this option. As the four nuclear plants cover about $40 \%$ of Swiss electricity generation, this opens the question how the future generation portfolio is supposed to look like if at the same time the carbon emission restrictions are to be kept.

Following this dramatic shift of direction in energy policy, policy makers are in need of guidance from energy-economic models regarding policy options and their feasibility. While a number of models exist in this regard (see the literature review in section 2), there is no techno-economic electricity market model for Switzerland taking both the transmission network as well as hydrologic interdependencies into account.

The objective of this paper is to develop an according model of the Swiss electricity market using the DC load flow approach coupled with a detailed representation of the underlying hydrological system of interlinked lakes and rivers to capture the most important electricity source in the country adequately. This model of the Swiss electricity market, termed Swissmod, will provide a flexible platform for a wide array of questions in regard to the future development of the Swiss electricity system and more general market and environmental research questions.

The remainder of this paper is structured as follows. The relevant literature is presented 
in section 2. In section 3 we present the model. Section 4 describes the underlying dataset and parameterization of the model. In section 5 the calibration of the model to ex-post observed data for 2012 is discussed. Section 6 provides a first glance at calculated nodal price patterns in Switzerland and section 7 concludes.

\section{Literature review}

Following the Swiss Energy Strategy 2050, the reports by Prognos AG (2012) and Ecoplan (2012) provide an estimation of the development of Swiss energy system till 2050 with different policy scenarios and an assessment of the subsequent economic consequences of those scenarios.

The electricity market plays a key role in this future development besides the building and transport sector. Within the electricity sector transmission and network related issues are crucial as they link generation and demand. An insufficient development of the network can hinder both the deployment of renewable generation and the establishment of demand side participation and energy efficiency approaches. A short report by the Swiss Federal Office

of Energy (BFE 2011) provides a first assessment of the required network related issues that need to be addressed within the energy strategy. These include the necessary extension of the transmission grid, capacity shortages in the distribution system, new transport options like DC transmission, and smart grid developments. In subsequent reports those issues have been addressed in more detail. Consentec (2012a) provides an estimate of the transmission network development regarding congestion and the resulting extension requirements based on the expected generation scenarios. Since a large share of Switzerland's grid utilization is induced by European transactions, the analysis is based on a European network model. Consentec (2012b) provides estimates of the requirements in the distribution system due to increased decentralized generation till 2050. The results are transformed into policy recommendation in $\mathrm{BFE}(2012 \mathrm{a})$ that include a faster network extension and transformation 
towards smart grids and a higher coordination with Europe.

To cope with the challenges and provide the theoretical and empirical background for policy makers the modeling of energy markets plays and will continue to play an important role. Mathys et al. (2012) highlight this role and provide an overview of nine existing modeling approaches for Switzerland. They classify nine models according to their typology as bottom-up, top-down, or in-between hybrid approaches. Within the bottom-up group are the ETEM model of regional energy systems (Babonneau et al. 2012), the Swiss MARKAL model covering the whole Swiss energy system and its successor Swiss TIMES with a focus on the electricity sector (Weidmann et al. 2012). Those models usually apply a high level of technological detail and a corresponding regional representation. Contrary, the top-down approaches follow the Computable General Equilibrium framework. Consequently, they cover the Swiss energy system in a more aggregated manner than the bottom-up approaches but can address macroeconomic aspects. The MERGE-ETL model (Marcucci and Turton 2012 ) is bridging those two approaches, combining a top-down model of the economy with a bottom-up representation of the energy system. All of those model approaches do not address the electricity network and, in general, cover the complexity of the Swiss electricity market in an aggregated and simplified manner (Mathys et al. 2012).

Indeed, the number of available detailed electricity market models of Switzerland is limited. The above mentioned Swiss TIMES model covers the whole electricity system, has an hourly resolution, and is calibrated to observed market results. Based on cost optimizations different scenario settings can be analyzed, e.g. supply options for replacing the nuclear power plants (Kannan and Turton 2012). Regarding hydropower, Balmer et al. (2006) set up an extensive model of the Swiss hydro electricity system. They employ a cost minimizing investment model with a 2030 model horizon in a European setting, coupled with a detailed representation of 149 hydropower plants within Switzerland.

Furthermore, several electricity market models cover the whole European grid and consequently also the Swiss electricity market (e.g. Consentec 2012a b; Leuthold et al. 2012; 
Stigler and Todem 2005). However, they normally need to take simplifications with respect to the detail level of individual countries.

\section{Model}

The model is designed as a linear cost minimization, coded in GAMS (General Algebraic Modeling System) and solved using the IBM CPLEX solver. We follow the DC load flow approach by Schweppe et al. (1988) and Leuthold et al. (2012) to model an electricity transmission system with a nodal pricing approach. Swissmod covers the whole transmission system of Switzerland as well as its interconnections to neighboring countries. Generation and demand is allocated on a nodal basis to allow an estimation of congestion aspects.

The model captures all forms of hydroelectricity in Switzerland: run-of-river, storage and pumped-storage power plants. Using a separate network, the hydraulic system of Switzer-

land is modeled using a dataset from the Swiss Federal Office of Topography (SwissTopo) containing all rivers and lakes in the country. Using this hydraulic network, water flows in the system are endogenously determined, so that the outflow of an upstream hydropower plant results in an inflow to a downstream power plant with a defined time lag. Since storage possibilities (upper basin, lower basin) are modeled, the available water resources are used efficiently by the system.

\subsection{Notation}

Table 1 indicates the used notation. The power grid network incidence matrix contains elements of $\{0,1,-1\}$ to connect nodes and lines in a directed graph, all other incidence matrices used contain binary elements of $\{0,1\}$ to indicate relationships. In the case of electricity lines $l \in L$, a value of $\mathbf{i}_{l, n x}=1$ and $\mathbf{i}_{l, n y}=-1$ denotes the start of a line at node $n x$ and end of the line at node $n y$. For all other matrices, a value of 1 means the object is connected to that node and a value of 0 that it is not. The relations (such as the power 
plant to power node relation $\mathbf{c p i}_{c p p}^{n}$ ) are of the "1:n" type, so that a node can have multiple power plants connected to it, but a power plant only has a single node.

\begin{tabular}{|c|c|c|c|c|}
\hline \multicolumn{3}{|c|}{ Indices / Sets: * } & \multicolumn{2}{|c|}{ Variables } \\
\hline \multicolumn{2}{|l|}{$n \in N$} & Power nodes & & \\
\hline \multicolumn{2}{|l|}{$l \in L$} & Power lines & & \\
\hline \multicolumn{2}{|l|}{$t \in T$} & Time periods & & \\
\hline \multicolumn{2}{|c|}{$c p p \in C P P$} & Conventional power plants & $w$ & \\
\hline \multirow{3}{*}{\multicolumn{2}{|c|}{$\begin{array}{l}h p p \in H P P \\
w n, l w n, \\
u w n \in W N\end{array}$}} & Hvdropower plants & $X$ & Phase angle difference \\
\hline & & Whator podoc (lowor & $W S$ & Storage content \\
\hline & & & $\Delta W S$ & Storage addition \\
\hline & & & $W I$ & Water inflow \\
\hline \multicolumn{3}{|c|}{ Special scripts: } & $W O$ & Water outflow \\
\hline$\square \uparrow$ & \multicolumn{2}{|c|}{ Hydro pumping } & $\vec{W}$ & Water flowing to next node \\
\hline$\square \downarrow$ & \multicolumn{2}{|c|}{ Hydro generation } & $C$ & Total generation cost \\
\hline $\bar{\square}$ & \multicolumn{2}{|c|}{ Upper limit } & & \\
\hline \multicolumn{3}{|l|}{ Matrices } & \multicolumn{2}{|c|}{ Parameters } \\
\hline $\mathbf{i}_{l, n}$ & & wer grid incidence & $e$ & Electricity (e.g. capacity in MW) \\
\hline $\mathbf{c p i}_{c p p}^{n}$ & & nventional plant incidence & $b$ & Power line susceptance \\
\hline $\mathbf{h p i} \mathbf{i}_{h p p}^{n}$ & & dro plant incidence & $v c$ & Variable cost \\
\hline $\mathbf{u p r}_{h p p}^{w n}$ & & ant upper water node & $\alpha$ & Production equivalent \\
\hline $\mathbf{l} \mathbf{w} \mathbf{r}_{h p p}^{w n}$ & & ant lower water node & $\beta$ & Pumping efficiency factor \\
\hline $\operatorname{lag}_{l w n}^{u w n}$ & & ater delay time & $d$ & Power demand \\
\hline$\theta_{l w n}^{u w n}$ & & ater node successor matrix & $\stackrel{\leftrightarrow}{w}$ & Local inflow to water node \\
\hline
\end{tabular}

Table 1: Notation

* Note that when an index is used without a set in the model, it is meant to iterate over the full set. 


\section{$3.2 \quad$ Electricity market model}

The objective of the model is to minimize total costs (Eq. 1) subject to the constraints detailed below in equations 2 to 17 . The costs represent the variable costs of conventional power plants over all time periods.

$$
\min _{e_{t}^{c p p}, e \uparrow_{t}^{h p p}, e_{t}^{h p p}}\left\{C=\sum_{t} \sum_{c p p} v c^{c p p} E_{t}^{c p p}\right\}
$$

Power flow calculation is based on the DC load flow approach following Schweppe et al. (1988) and Leuthold et al. (2012) to model an electricity transmission system with a nodal pricing approach. Therefore, power flows in an AC grid are simplified to a DC load flow (DCLF) approach, using the assumptions made in Stigler and Todem (2005) regarding voltage angle differences, so that power flow on a line can be calculated as the susceptance $b^{l}$ times the phase angle difference between start and end node of a line. Given the definition of the incidence matrix $\mathbf{i}_{l, n}$ and the phase angle $X_{t}^{n}$, Eq. 2 captures this relationship.

$$
E_{t}^{l}=b^{l} \sum_{n} \mathbf{i}_{l, n} X_{t}^{n} \quad \forall l, t
$$

By means of Eq. 3, the slack bus is arbitrarily fixed to node $n 1$, so that all phase angles $X_{t}^{n}$ are relative to that of node $n 1$.

$$
X_{t}^{n 1}=0 \quad \forall t
$$

To ensure that each node is in balance, we apply Kirchhoff's law (Eq. 4), stating that the sum of all flows into and out of a node is always equal to the net input $E_{t}^{n}$ at that node.

$$
E_{t}^{n}=\sum_{l} \mathbf{i}_{l, n} E_{t}^{l} \quad \forall n, t
$$

The net input at a node furthermore has to be equal to the sum of power produced from conventional power plants $E_{t}^{c p p}$ and hydropower plants $E \downarrow_{t}^{h p p}$, minus the sum of electricity needed by hydropower plants to pump up $E \uparrow_{t}^{h p p}$ and exogenous consumer demand $d_{t}^{n}$ (Eq. 5). The multiplication with incidence matrices (here: $\mathbf{c p i}$ and $\mathbf{h p i}$ ) ensures that only those power plants, which are actually connected to the node, are included in the node's balance. 


$$
E_{t}^{n}=\sum_{c p p} \mathbf{c p} \mathbf{i}_{c p p}^{n} E_{t}^{c p p}+\sum_{h p p} \mathbf{h} \mathbf{i}_{h p p}^{n} E \downarrow_{t}^{h p p}-\sum_{h p p} \mathbf{h p i}_{h p p}^{n} E \uparrow_{t}^{h p p}-d_{t}^{n} \quad \forall n, t
$$

Equations 6 and 7 ensure that postive and negative power flows $E_{t}^{l}$ never exceed the line capacity limit $\bar{e}^{l}$.

$$
\begin{array}{cl}
E_{t}^{l}<\bar{e}^{l} & \forall l, t \\
E_{t}^{l}>-\bar{e}^{l} & \forall l, t
\end{array}
$$

Fossil fuelled power plants are modelled schematically. We consider only variable costs and neglect start-up costs and ramping constraints. The only constraint conventional power plants are facing is the capacity constraint (Eq. 8).

$$
E_{t}^{c p p}<\bar{e}^{c p p} \quad \forall c p p, t
$$

\subsection{Hydropower system}

The hydropower system is modelled in detail, both with respect to the types of hydropower plants available as well as regarding the country's hydrological system of lakes and water streams.

\subsubsection{Hydropower plants}

Even though there are different types of hydropower plants (mainly run-of-river, yearly storage and pumped-storage power plants), they are modelled analogously in the model, yet with different parameters for each of the types (or more precisely, for each individual plant). The parameters describing a hydropower plant are its turbine capacity $\overline{e \downarrow}^{h p p}$ (i.e. capacity when generating electricity), its pumping capacity $\overline{e \uparrow}^{h p p}$ (i.e. capacity when pumping water upwards) as well as the specific production equivalent (MWh of electricity generated per metric ton of water) $\alpha^{h p p}$. The latter depends on the turbine technology as well as the fall height between upper basin and lower basin of the plant. Additionally, for those plants which have a pump capacity $\overline{e \uparrow}^{h p p}>0$, the parameter $\beta^{h p p}$ specifies the pump efficiency, 
that is the ratio of electricity needed to pump up a certain amount of water divided by the electricity generated from turbinating the same quantity of water.

Equations 9 to 12 characterize the functioning of hydropower plants. Equations 9 and 10 describe the production function relation of hydropower plants in converting movements of water $W$ to electricity $E$ and vice versa. While Eq. 9 determines that relationship during discharging (i.e. electricity generation), Eq. 10 determines the relationship for the case of pumping water upwards (consuming electricity).

$$
\begin{array}{ccc}
E \downarrow_{t}^{h p p}=\alpha^{h p p} W \downarrow_{t}^{h p p} & \forall h p p, t \\
E \uparrow_{t}^{h p p}=\frac{\alpha^{h p p} W \uparrow_{t}^{h p p}}{\beta^{h p p}} & \forall h p p, t \\
E \downarrow_{t}^{h p p} & <\overline{e \downarrow}^{h p p} & \forall h p p, t \\
E \uparrow_{t}^{h p p} & <\overline{e \uparrow}^{h p p} & \forall h p p, t
\end{array}
$$

Like conventional power plants, hydropower plants are also bound to capacity restrictions, both when turbinating (Eq. 11) and when pumping water back up (Eq. 12) to the upper water node.

\subsubsection{Hydrological network}

Many electricity market models such as STEM-E (Kannan and Turton 2012) and Swiss TIMES (Weidmann et al. 2012) as well as nodal pricing electricity dispatch models (such as Leuthold et al.2012 or Stigler and Todem 2005) consider hydropower plants on an aggregated or individual basis only, disregarding the fact that plants are interconnected by means of rivers and water streams. This aspect is explicitly modeled in Swissmod.

For modeling purposes, the country's complex hydrologic topology is reduced to points in the network which are relevant for hydroelectricity production. Relevant in this regard are all connections of hydropower plants to the river network (i.e. the upper water nodes and lower water nodes of each hydropower plant) and each point in the hydrological system where two 
river streams confluence to one. Modeling these points is important in order to capture the fact that downstream hydropower plants receive the outflow of upstream hydropower plants. Depending on the placement of the plants along river flows, a hydropower plant could receive inflows of different streams further up in the cascade. Each point in the hydrological system relevant to the model is called a water node $w n$.

Water flows $\vec{W}_{t}^{w n}$ in the hydrological system are characterized by two parameters; the share $\theta_{l w n}^{u w n}$ of an upper water node uwn's outflow to end up as inflow to a lower water node lwn and the water delay time for water to make the way from the upper to the lower node $\operatorname{lag}_{l w n}^{u w n}$.

Apart from the water flows in the hydrologic system, water can be either discharged or pumped up by hydropower plants. Since each hydropower plant is connected to an upper water node by $\mathbf{u p r}_{h p p}^{w n}$ and to a lower water node by $\mathbf{l w r}_{h p p}^{w n}$, the inflow of a water node from hydropower plants is equal to $\sum_{h p p}\left(\mathbf{l} \mathbf{w} \mathbf{r}_{h p p}^{w n} W \downarrow_{t}^{h p p}\right)+\sum_{h p p}\left(\mathbf{u p r}_{h p p}^{w n} W \uparrow_{t}^{h p p}\right)$, i.e. the outflow of hydropower plants, of which the current water node is the lower node, as well as the water pumped up by hydropower plants, of which the current water node is the upper node. Combined with an exogenous local inflow of $\stackrel{\circ}{w}_{t}^{w n}$, this results in the total inflows $W I_{t}^{w n}$ defined in Eq. 13. Likewise, the outflows $W O_{t}^{w n}$ are described in Eq. 14 and describe the opposite side.

$$
\begin{gathered}
W I_{t}^{w n}=\stackrel{\circ}{w}_{t}^{w n}+\sum_{h p p} \mathbf{l} \mathbf{w} \mathbf{r}_{h p p}^{w n} W \downarrow_{t}^{h p p}+\sum_{h p p} \mathbf{u p r}_{h p p}^{w n} W \uparrow_{t}^{h p p}+\sum_{u w n} \theta_{w n}^{u w n} \vec{W}_{t-\mathbf{l a g}_{w n}^{u w n}}^{u w n} \forall w n, t \\
W O_{t}^{w n}=\sum_{h p p} \mathbf{u p r}_{h p p}^{w n} W \downarrow_{t}^{h p p}+\sum_{h p p} \mathbf{l} \mathbf{w} \mathbf{r}_{h p p}^{w n} W \uparrow_{t}^{h p p}+\sum_{l w n} \theta_{l w n}^{w n} \vec{W}_{t}^{w n} \forall w n, t
\end{gathered}
$$

There is no constraint in the model to disallow spillage (i.e. water flows parallel to hydropower plants without generating electricity), although optimization is likely to result in this being used rarely and in special circumstances only.

Water nodes with storage capacity $\overline{w s}$ wn $>0$ can be used to store water and thereby represent storage basins of hydropower plants. The changes of storage contents $\Delta W S_{t}^{w n}$ (net water added to the storage lake in $t$ ) are given by Eq. 15; the maximum storage level is 
ensured by Eq. 16 .

$$
\begin{gathered}
\Delta W S_{t}^{w n}=W S_{t}^{w n}-W S_{t-1}^{w n} \quad \forall w n, t \\
W S_{t}^{w n}<\overline{w s}^{w n}
\end{gathered}
$$

Finally, Eq. 17 ensures that a water node is always in balance.

$$
W O_{t}^{w n}=W I_{t}^{w n}-\Delta W S_{t}^{w n} \quad \forall w n, t
$$

Given the parameters and equations above, it is now possible to distinguish the different types of hydropower plants as depicted in Table 2. While generation capacity and pump capacity is a parameter of the hydropower plant itself, the difference between plants which can store water and those which cannot comes from the storage capacity $\overline{w s}{ }^{w n}$ of the upper water node.

\begin{tabular}{l|l|l|l}
\hline \hline Plant type & $\begin{array}{l}\text { Generation capacity) } \\
\frac{e \downarrow}{e p p}\end{array}$ & $\begin{array}{l}\text { Pump capacity) } \\
\frac{e \uparrow}{h p p}\end{array}$ & $\begin{array}{l}\text { Upper basin storage } \\
\frac{w s}{w n}\end{array}$ \\
\hline Run-of-river plant & $>0$ & - & - \\
Storage plant & $>0$ & - & $>0$ \\
Pumped storage plant & $>0$ & $>0$ & $>0$ \\
\hline
\end{tabular}

Table 2: Parameterization of hydropower plants

\section{Data}

We parametrize the model to the Swiss electricity market including the transmission network, nuclear and hydro supply, demand and neighboring countries' supply and demand structure.

Given the nature of the nodal pricing model implemented, not only the elements (grid, supply, demand) themselves are important for the model, but also their geographical location and interrelation. Therefore, a Geographic Information System (GIS) connected to a spatial 


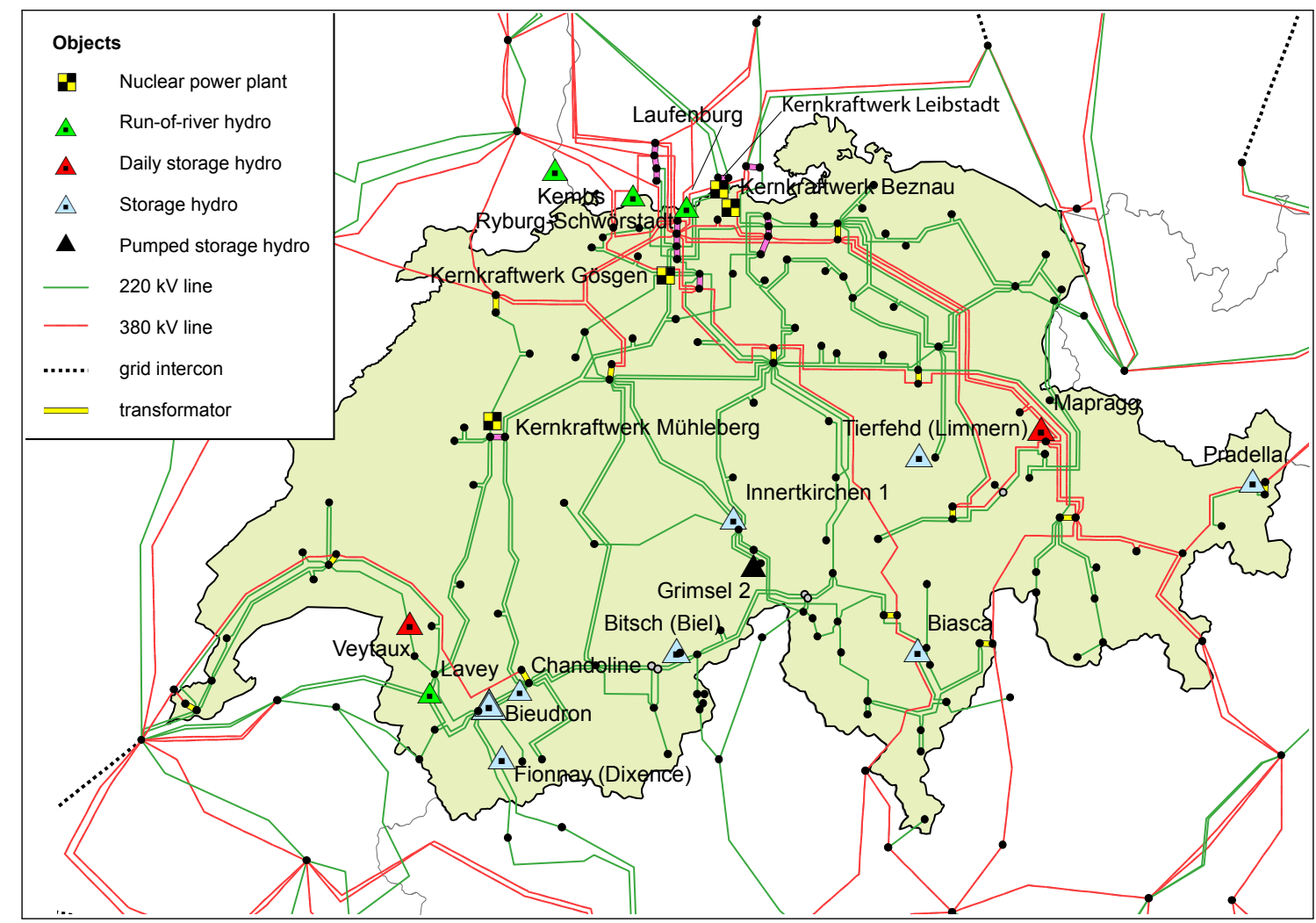

Figure 1: All model parameters are stored in a Geographic Information System (GIS)

database is used to maintain all data used in the model.

\subsection{Electricity grid}

We reproduce the Swiss transmission grid from a map published in Swissgrid (2012). The location of some substations is corrected based on more detailed information available in the collaborative mapping project OpenStreetMap. As a result, a sufficiently accurate schematic geographical map of the Swiss high voltage $(220 \mathrm{kV}$ and $380 \mathrm{kV})$ transmission grid is produced, including the location of substations as well as the number of parallel lines and the types of lines (Figure 1). We use this representation in the spatial database to generate the network incidence matrix. We derive the respective resistance, susceptance and capacity values of transmission lines from calculated line lengths from the GIS system and assumed standard values for the line types from Fischer and Kießling (1989).

To account for the security margin usually present in transmission networks (also known 
as n-1 criterion), we leave a general security margin of $25 \%$ line capacity unused in each line, i.e. calibrating lines to $75 \%$ of line capacity. While this is not an exact measure of n-1 security, it does ensure the model results are closer to realistic values.

All cross-border lines among the neighbouring countries and from the neighbouring countries to Switzerland are recreated from the official ENTSO-E grid map and set to the transfer capacity values from ENTSO-E (2013) data.

\subsection{Power plants}

The supply side of the Swiss electricity sector is mostly based on hydro and nuclear power and only few remaining percentage points are served by other energy sources such as conventional fossil fuels and renewables. Therefore, special emphasis lies on hydropower and the nuclear power plants in Switzerland.

\subsubsection{Thermal power plants}

Swiss nuclear power plants account for about $40 \%$ of Swiss electricity supply. The location and capacity parameters of the nuclear plants were obtained from the GIS database "Geobasisdaten" of the Swiss Federal Office of Energy. A remainder of around 5\% of Swiss electricity supply is labelled as "conventional thermal and other power plants" in Swiss statistics (BFE 2013), which includes waste and combined heat and power plants as well as solar and wind power. As no detailed data on these "other" power plants is available, they are subtracted evenly from demand. Swiss hourly statistics for the " $3^{\text {rd }}$ Wednesdays of each month in 2012" (ibid.) show that this residual supply hardly reacts to demand, so the assumption of equal distribution to all hours to reduce residual demand seems justifiable. The geographic incidence of this share of supply however is uncertain and the equal geographic distribution is inaccurate. 


\subsubsection{Hydropower}

Accounting for $55 \%$ of the Swiss electricity supply, hydropower is Switzerland's most important electricity source. For the modelling purposes, it is important not only to capture the total extent of hydropower in aggregate but also the individual hydropower plants with their geographic location, available technical characteristics (power of turbines, pumping ability, height of fall, etc.) and information on which bodies of water (river, lake, storage basin) they are connected to. Most of the necessary information was available from the Swiss Federal Office of Energy (BFE) as a geographic dataset (BFE 2012b) which could be included in the Swissmod spatial database. A "find nearest node" operation in the GIS system was performed to find the nearest electricity substation to a hydropower plant in order to approximate which nodes in the electricity grid a hydropower plant is connected to. As a proxy for the production equivalent we use the ratio between maximum electrical capacity of the turbines in $M W$ and the maximum water throughput in $m^{3}$.

Detailed data of the river system in Switzerland (GWN/Vector 25 by swisstopo) was used to derive the hydro cascade incidence matrix. This dataset includes all water bodies in Switzerland on a detailed level, from small streams or ponds to the largest rivers. By manual work in GIS, each bigger hydropower plant $(>250 \mathrm{MW})^{1}$ is connected to one preceding water node (upper node) and one succeeding water node (lower node).

Based on this mapping, it is then possible to extract the following parameters necessary for the model:

- Hydro cascade incidence $\left(\theta_{l w n}^{u w n}\right)$

- Water delay time $\left(\mathbf{l a g}_{l w n}^{u w n}\right)$

- Hydro plant to upper and lower water body incidence $\left(\mathbf{u p r}_{h p p}^{w n}\right.$ and $\left.\mathbf{l w} \mathbf{r}_{h p p}^{w n}\right)$

To extract this data from the aforementioned GIS dataset of river streams, we develop a script connected to the GIS system, which traverses the river flows included in the dataset

\footnotetext{
${ }^{1}$ In a subsequent model version, it is planned to extend the selection of hydropower plants.
} 
starting from all connection points of hydropower plants and ending at the end of the river systems at the Swiss border. In between hydropower plants, it calculates time lags (based on an assumed water velocity of constant $8 \mathrm{~km} / \mathrm{h})^{2}$ as well as the local inflow. As we do not have a dataset on local inflow to points along rivers across Switerland, we derive this data from the discharge and catchment area dataset from BAFU (2012) which we link to the GWN water network. We assume local inflow to be the difference between discharge at any water node and inflows from incoming water streams. The script calculates this information for each point in the water system to which a hydropower plant is connected to the point where two rivers with connected hydropower plants intersect.

Since the data source we use (ibid.) is based on models rather than historical observations, it does not match the realistic absolute amount of water inflow for all locations. To ensure that each hydropower plant receives at least the water necessary to generate its yearly average electricity production, we scale the inflow to the respective level. This alters the absolute values but leaves the seasonal month-by-month patterns intact.

\subsection{Neighboring countries and import/export}

In order to account for the fact that Switzerland is highly interconnected with its neighbouring countries, the neighbouring countries Austria, Italy, France and Germany are included schematically in the grid map with two to three aggregate regional nodes as well as one generic node per country. On these nodes, the full power plant portfolio, cost structures and hourly demand of the covered region is aggregated.

Thermal restrictions such as start-up costs, ramping constraints or part-load efficiency in power plants of the neighbouring countries are not taken into account, since for those countries we include only the overall capacity of a particular technology and not the individual plants. The power plant and cost structure data are obtained from the ELMOD modelling community (see e.g. Egerer et al. 2014; Leuthold et al. 2012) and updated using data from

\footnotetext{
${ }^{2}$ This will have to be calibrated more precisely in a subsequent version of the model.
} 
ENTSO-E (2013). Monthly fuel costs for gas fired power plants are obtained from Eurelectric (2013), those for coal fired power plants from the German Federal Office of Economics and Export Control BAFA (2014).

The country nodes are connected to all cross-border power lines that connect the countries with Switzerland. Also, cross-border power lines between the different neighbouring countries are included, so that Switzerland is embedded in a "spider web" of neighbouring countries. Import and export values of all modelled countries are then endogenously determined as part of the overall cost minimization approach.

For variable renewable energy (VRE) capacities are also taken from the ELMOD database. The time incidence of renewable's production in the benchmark year 2012 is taken from the EEX transparency platform. The German time incidence of wind/solar production is used for the scaled VRE production of the other neighbouring countries, thus assuming perfect positive correlation across countries. VRE input is taken as exogenous supply and reduces demand at the specific nodes and time periods by the amount of VRE input.

\subsection{Demand}

Demand is taken as exogenous (assuming a price elasticity of zero) and the per-country ENTSO-E hourly load values for the year 2012 are used for calibration. As hourly load values for a full year do not sum up to the amount of electricity consumed from yearly statistics, we apply a scaling factor for hourly load values. This factor ranges from 1.0 for France to 1.14 for Germany. Net imports from third party countries which are not included in the model are subtracted from country demand. 


\subsubsection{Estimation of hourly load values for Switzerland}

Since the ENTSO-E hourly load values for Switzerland just represent net vertical load ${ }^{3}$ hourly load values are estimated from the given net vertical load values. As the values published for the $3^{\text {rd }}$ Wednesday of each month are, according to ENTSO-E, indeed the true load values, these are used to estimate load values for the remaining hours. To obtain estimators for the load values an ordinary least squares (OLS) regression is applied. The net vertical load values $(n v l)$ as well as month $m_{i}$ and year dummies $y_{j}$ are used to regress the $3^{\text {rd }}$ Wednesdays load data (load) as shown in Eq. 18.

$$
\text { load }=\alpha+\beta \cdot n v l+\gamma_{1} \cdot m_{1}+\ldots+\gamma_{11} \cdot m_{11}+\delta_{2012} \cdot y_{2012}+\delta_{2013} \cdot y_{2013}
$$

Subsequently, fitted values for all hours of the year are generated and used where the primary data is not available (e.g. for all days except the $3^{\text {rd }}$ Wednesdays of each month). With an $R^{2}$ of 0.88 the estimation provides a reasonable measure to derive hourly load values for the model. All coefficients at the 10 percent level are significant and most are even significant at the 0.1 percent level (see Appendix I).

\subsubsection{Regional demand disaggregation}

We disaggregate national demand for Switzerland to the 26 Swiss cantons in our model based on the number of inhabitants and GDP with data provided by the Swiss federal administration. Within the cantons, load is distributed equally to all nodes in the canton. Each node represents a substation transforming from high voltage transmission lines (220 or $380 \mathrm{kV}$ ) to the $110 \mathrm{kV}$ or lower voltage network.

\footnotetext{
${ }^{3}$ See https://www.entsoe.eu/fileadmin/user_upload/_library/publications/ce/Load_and_ Consumption_Data.pdf
} 


\section{Calibration}

In order to test our model and compare the results to reality, we calibrate it with data for 2012. The variables we calibrate for are monthly cross border flows for all endogenous borders (between Switzerland, Austria, France, Italy and Germany), monthly and yearly production volumes per technology and seasonal price patterns. The degrees of freedom in calibration are relative input price and capacity adjustments to match seasonally varying availability of capacity.

We fix available generating capacity of the typical base load technologies nuclear and lignite to the observed availability from ENTSO-E (2013) and thereby essentially predetermine their monthly output to the statistically observed one due to their position in the merit order. As most conventional power plants follow the same typical maintenance cycle of longer maintenance outages during low-load summer, we apply the average availability curve we observe over all countries' nuclear and lignite plants also to the remaining fossil power plants.

Regarding cross border flows (Figure 2), our model is able to reproduce most of the observable patterns, such as the generally large flows towards Italy as well as seasonal differences in flows between Switzerland and its neighbouring countries. The Austrian-German border generally shows lower power flows in our model than in the ENTSO-E statistics. This could be a result of our model being limited to the 220 and $380 \mathrm{kV}$ level, as especially in the Austrian-German border region, a number of cross border lines on $110 \mathrm{kV}$ level exist. Another divergence of model results from statistics occurs for the French-German border, where French exports to Germany are consistently lower than in reality and change sign for the beginning of the year. This could be in part due to counting of the Swiss-German substation Asphard for Switzerland only in our model, although in reality it is a shared substation of German TransnetBW and SwissGrid. Another factor distorting the flows on the French-German border could be the fact that we do not model the grid in the Benelux region (Belgium, Netherlands, Luxembourg) in detail, which could have an impact on resulting 


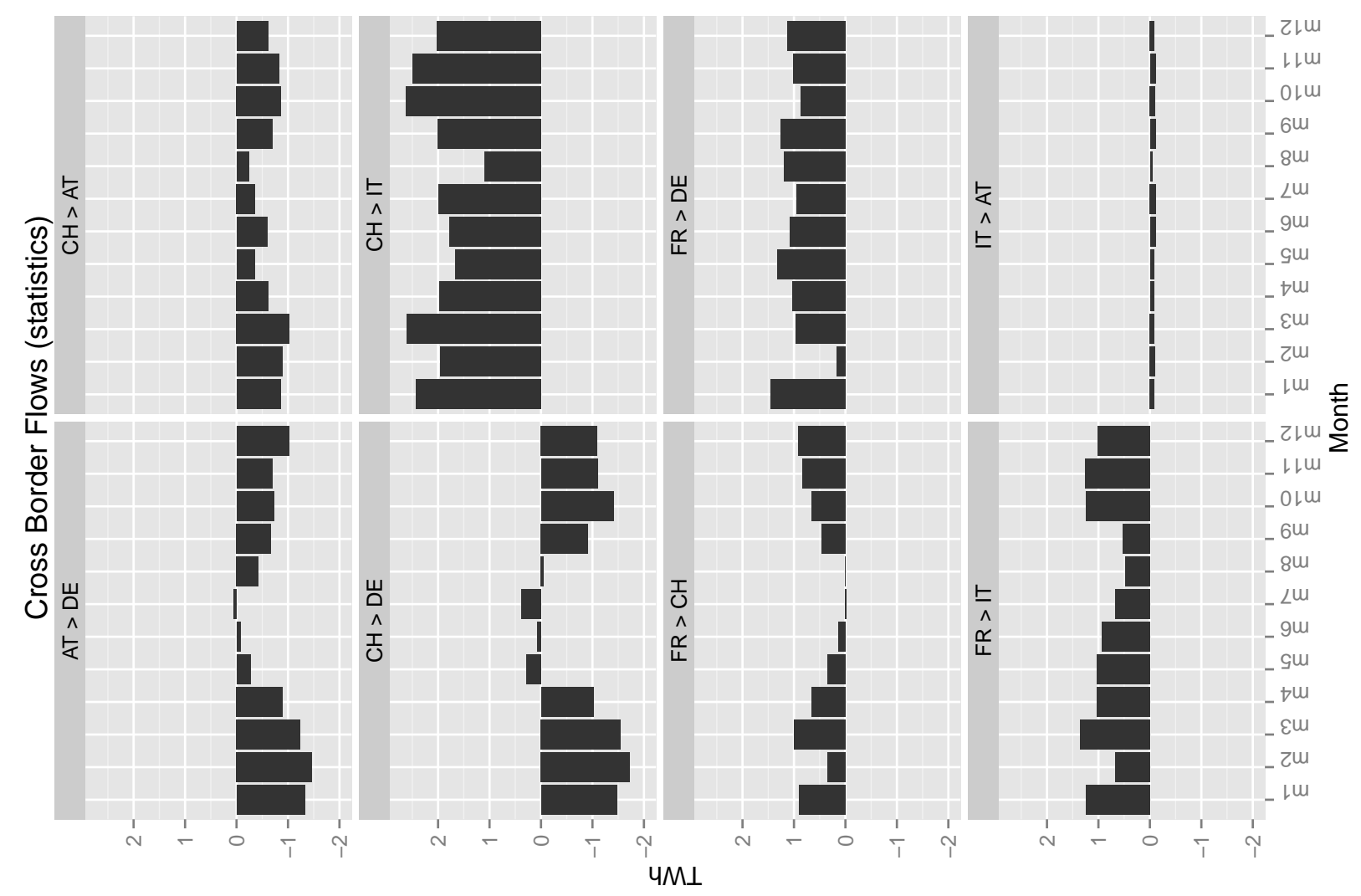

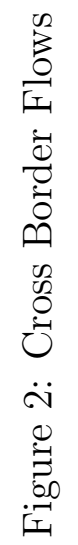

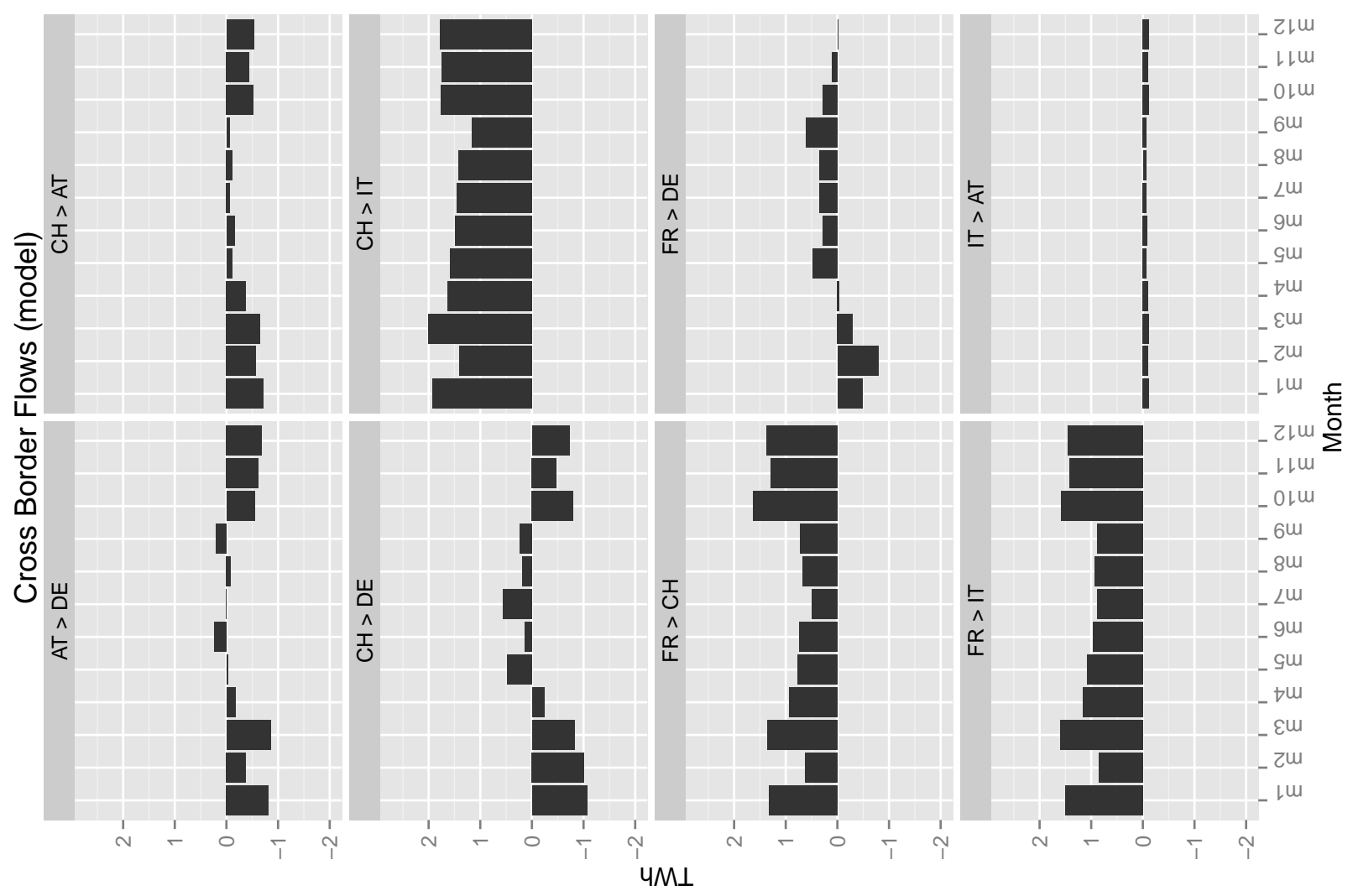


flows between Germany and France on their direct cross border lines.

Yearly power production (Figure 3) in our model also matches statistical data rather closely $\bigsqcup_{4}^{4}$ Significant divergence only occurs for Austrian fossil fuelled power plants, which are overused in our mode $]^{5}$ as well as German gas power plants.

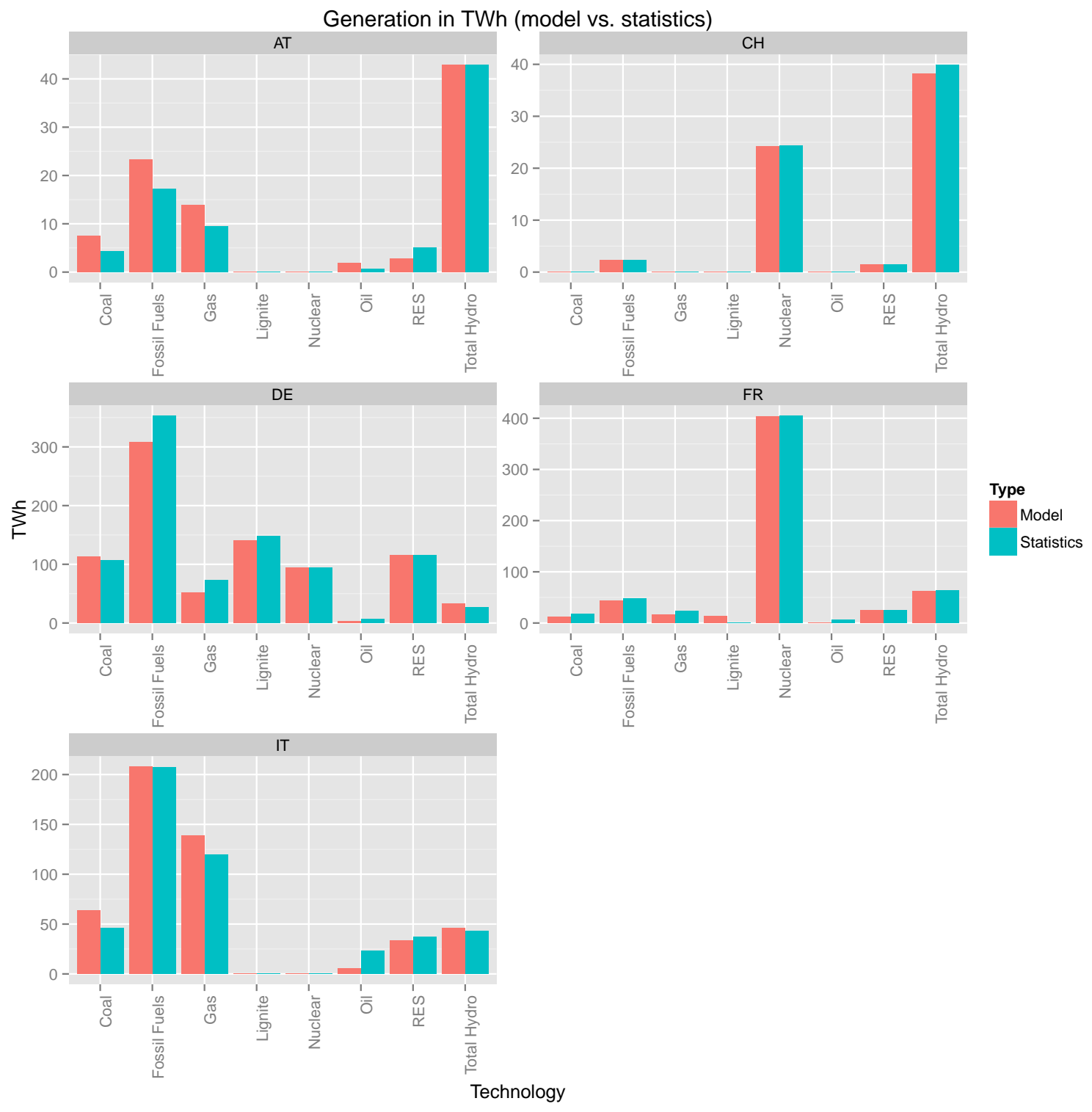

Figure 3: Yearly generation: Model output vs. ENTSO-E yearly statistics

\footnotetext{
${ }^{4}$ Production from power plants that is reported as "mixed fuel" in the ENTSO-E statistics is distributed to the power plant types known to Swissmod in the model.

${ }^{5}$ Part of the reason could be the large share of combined heat and power (CHP) for Austrian fossil fuelled power plants.
} 
Figure 4 shows the average power line usage over a full year within Switzerland resulting from our model. As comparable historical information is not available, we use a map by SwissGrid as benchmark which shows the incidence of n-1 criteria violations during a year from Swissgrid (2013). These give an indication of situations in which the security margin in the system is critically low, so that an additional fault of a single grid element would impede system stability. Comparing these to the electricity lines with high average use in our model, most n-1 violation hot spots in the SwissGrid map appear at least in the medium usage category in our model results. However, our model results do not confirm a frequent congestion of the north-south line Hautrive to St. Triphon, which appears in the highest category of n-1 violations in the SwissGrid map. In that area, our model finds the highest line use in the Battiaz (CH) - Valpelline (IT) cross border line. Also, the Avegno Magadino line does not appear to be used much in our system, while being a critical n-1 hot spot for SwissGrid. The hotspot in the Geneva region is confirmed by our model, equally to the medium high usage situation in the east of Switzerland between La Punt and Pradella as well as the one in north-west Switzerland. It must be noted, though, that $n-1$ criteria violations are not necessarily an indication of high average usage, so the comparision is to be taken cautiously.

Swissmod does not include phase angle shifters and we do not have information about their existence and location in neither Switzerland nor its neighbouring countries. Including their configuration could change power flows to some degree. Also, in the model all transmission lines that reach a certain node are connected with all other transmission lines on that node, which might not be the case in reality. 


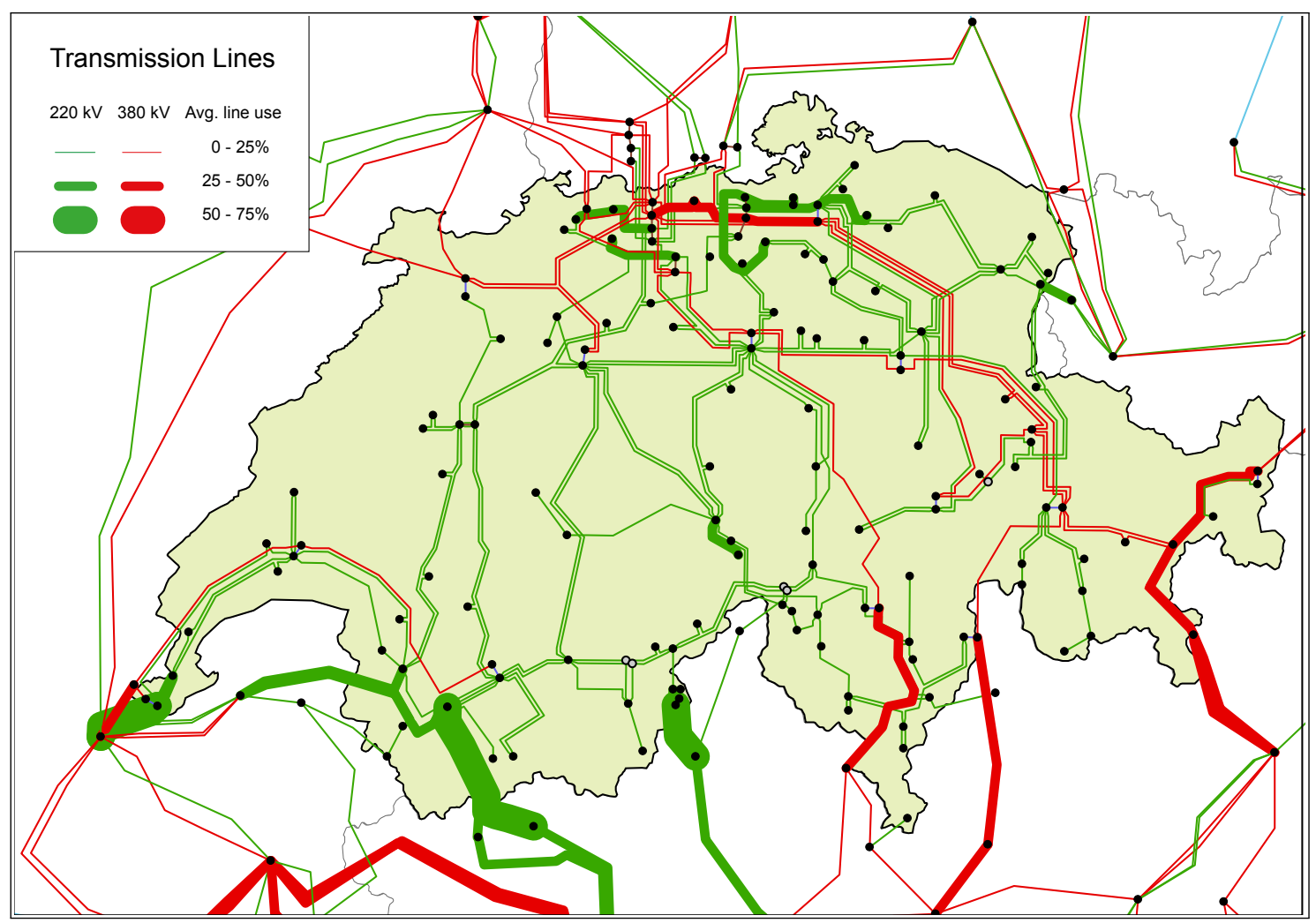

(a) Average line usage (model)

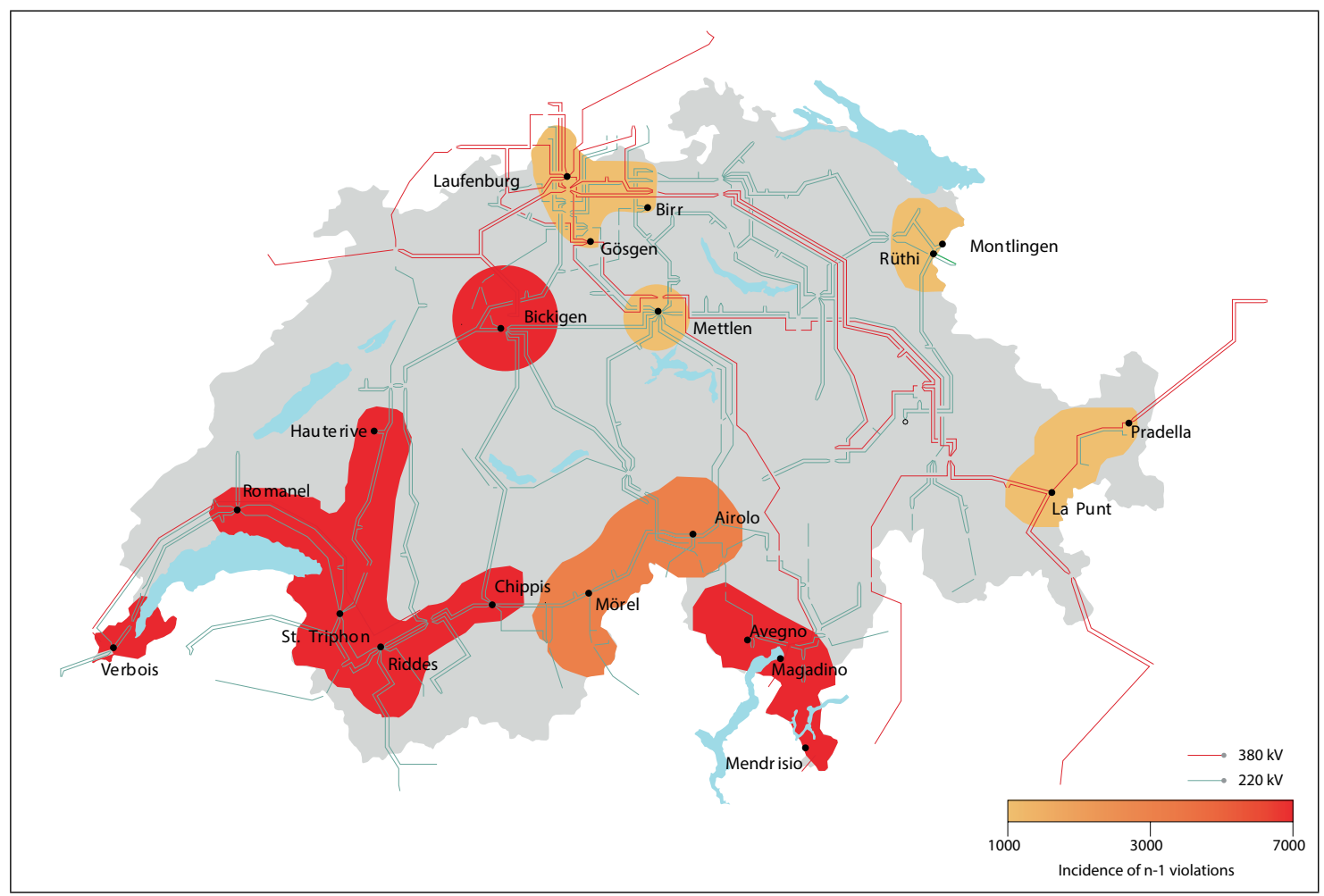

(b) SwissGrid n-1 violations (Source: ibid.)

Figure 4: Line usage maps (model vs. SwissGrid) 
One of the major aspects of the model is the ability to endogenously determine water levels of storage lakes and the resulting water flows. We fix the storage level in the first and last hour of the year, setting both to $60 \%$ to approximately match long-term average statistical values. Figure 5 shows the aggregated total storage curves (model vs. statistics) over the year. While the general shape of the curve depicting total hydro storage in our model resembles the statistical values, the spring and fall extreme values are more pronounced in our model. This can be attributed to the fact that the model is deterministic. While in reality hydropower operators need to account for the risk of unforseen inflows or draughts, our model assumes perfect information regarding hydropower inflows and thus can optimize accordingly.

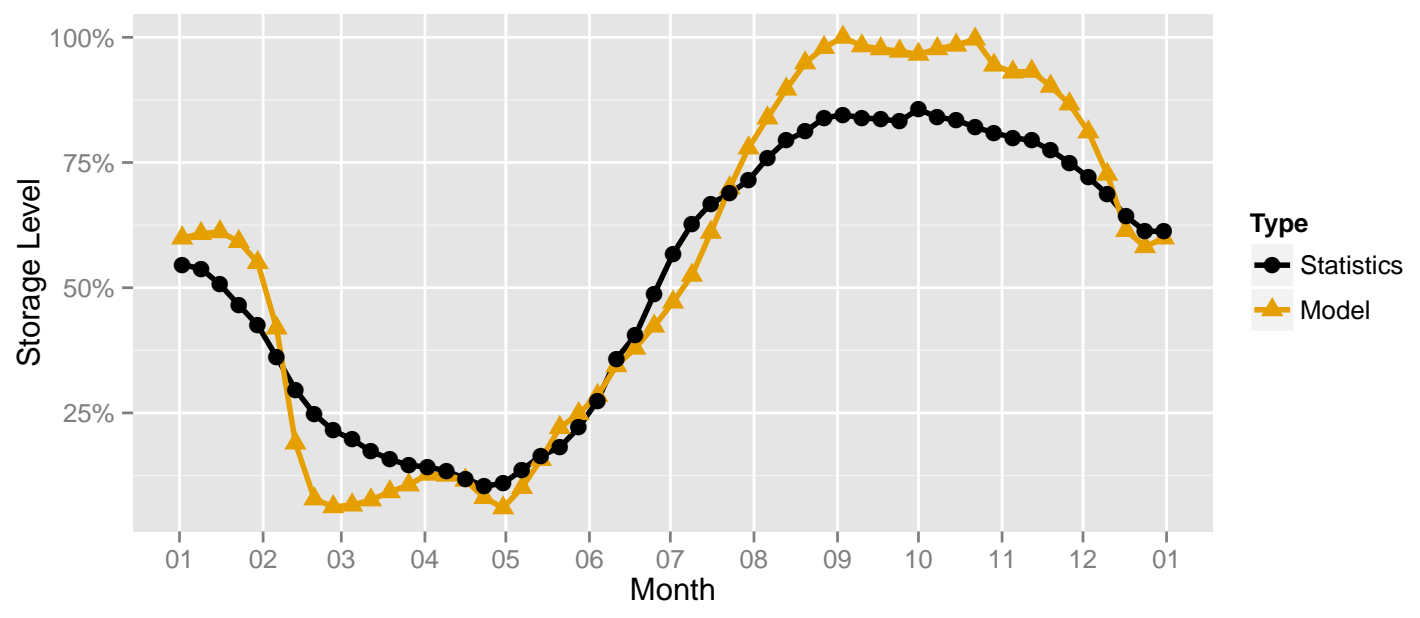

Figure 5: Storage levels (Model vs. BFE Statistics)

Price levels have been calibrated by a global price adjustment factor to account for the fact that the input fuel prices do not cover various side-costs to conventional generation such as transportation costs as well as the usage of generic plant efficiency factors. The resulting simulated seasonal price pattern (Figure 6) captures the essential movements of the actual price pattern ${ }^{6}$. However, the price spikes observed in reality are not as pronounced in our model.

\footnotetext{
${ }^{6}$ Note that in the "actual" figure the price for Germany is also applicable for Austria, as both countries are part of a single market area.
} 
This could be due to the simplified modelling of conventional power plants in Swissmod, which ignores start-up costs, ramping restrictions and other features of conventional power plants. Generally, Swiss prices appear slightly cheaper in our model than in reality.

Beside the simplifications in the unit commitment representation the deterministic nature of the model can lead to deviations between simulated and actual prices. Due to perfect foresight for the complete year the resulting dispatch and storage operation is optimized and the resulting price levels can be expected to be below market price levels that are influenced by uncertainty and imperfect information. Furthermore, the model includes a perfect market coupling within the modeled countries which on average should lead to more price convergence between the countries than in the real markets. However, due to the inclusion of a detailed network representation with load flow and security margins, the modeled market prices are subject to network congestion (see also next section) that is managed by re-dispatch in the real markets. This can lead to higher locational prices in Swissmod. Overall, the model calibration is focused on achieving a good match between observed aggregated generation levels and cross border patterns and the resulting prices have to be taken with care.

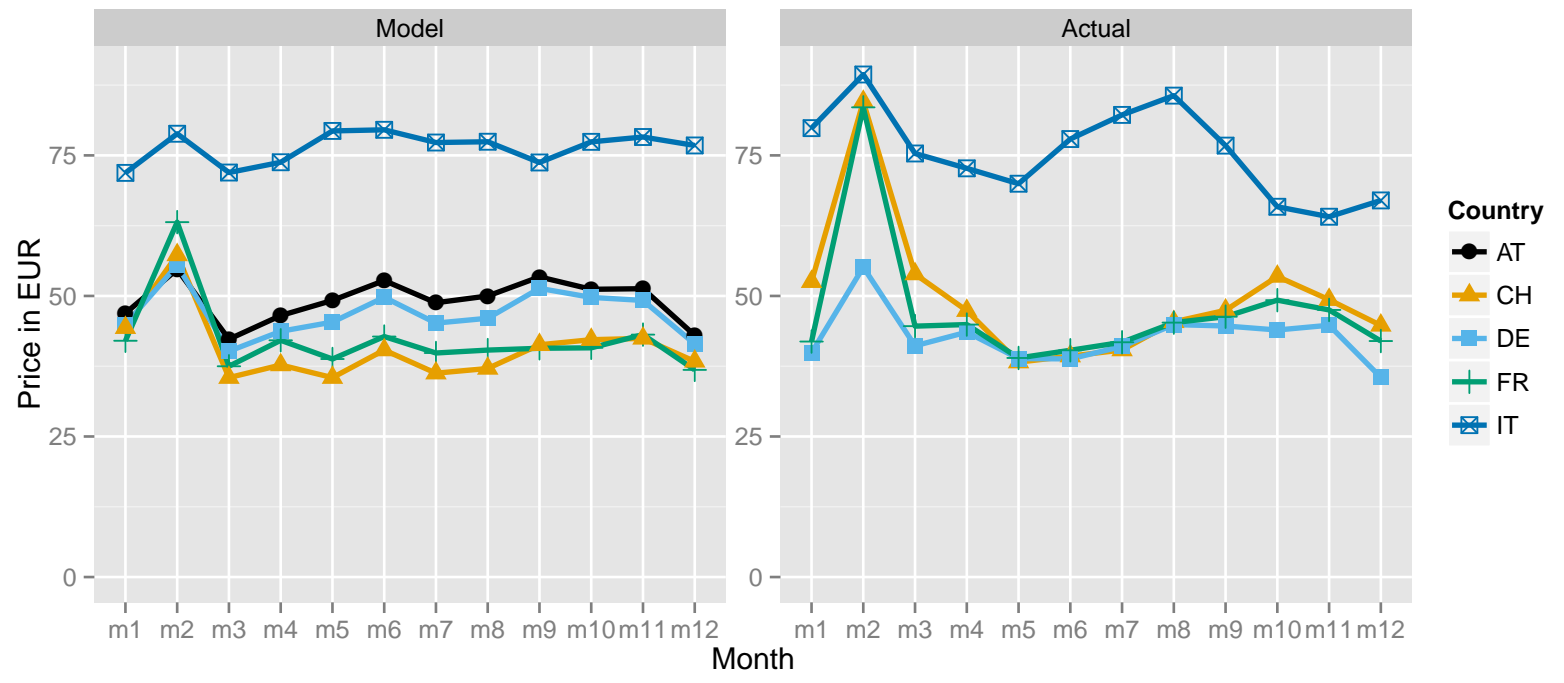

Figure 6: Monthly average prices (model vs. actual) 


\section{Nodal Prices in Switzerland}

The main purpose of the paper at hand is to outline the electricity market model Swissmod. As we are employing a nodal pricing model to analyse the Swiss electricity market, we can draw conclusions about regional price patterns already from our nodal representation of the Swiss electricity system in 2012 .

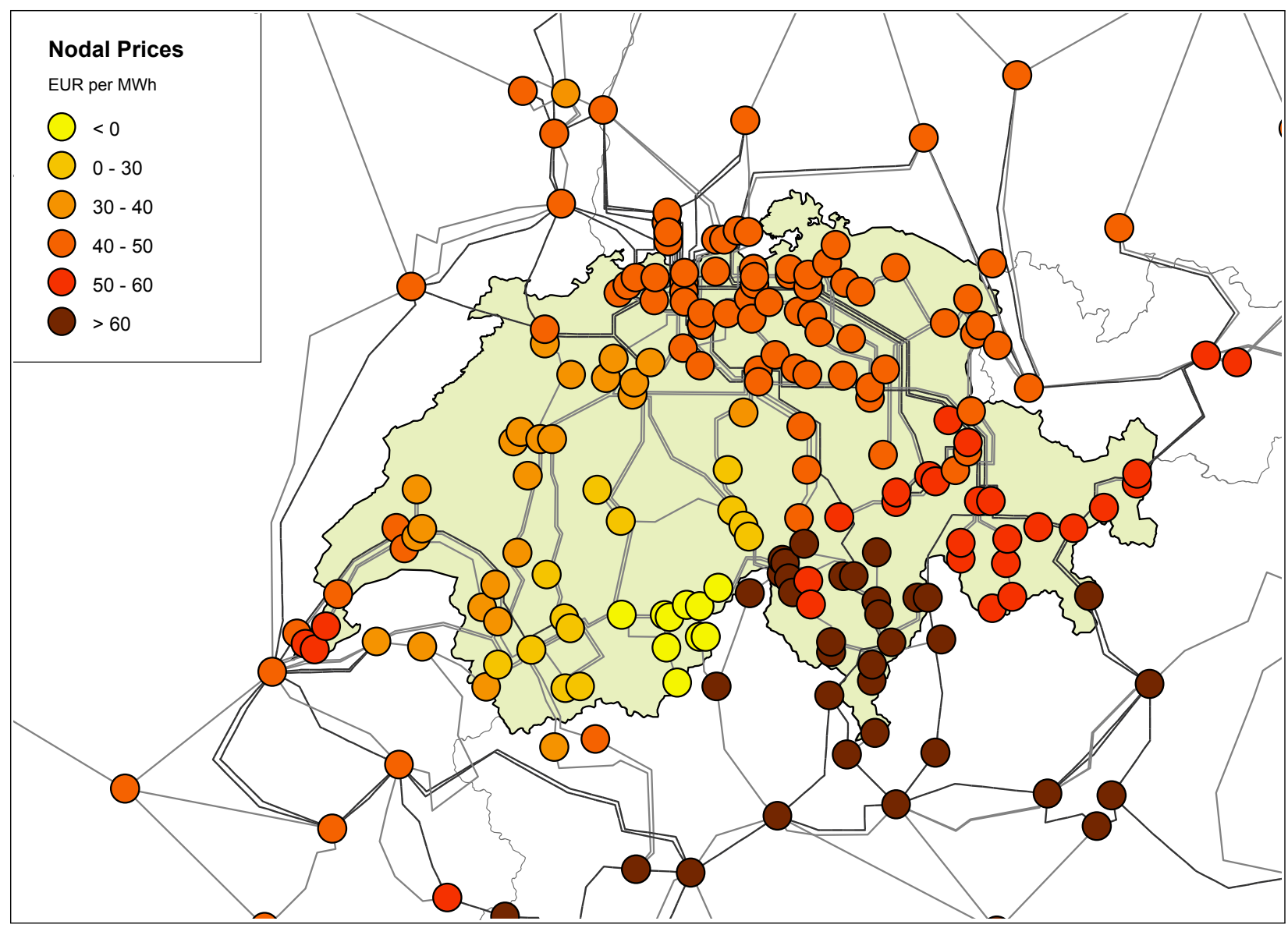

Figure 7: Map of yearly average nodal prices

Analysing average nodal prices across Switzerland (Figure 7) as resulting from our model, a clear differentiation of price regions becomes apparent. While the north seems to have rather high average prices in general, there are only few price differences, suggesting rather low line congestion. The opposite is true for the south of Switzerland, where both very high and very low nodal prices can be seen.

In the central southern part of Switzerland (eastern part of the canton of Valais) there 
seems to be a situation of oversupply and thus negative average prices, while neighbouring in the east the canton of Ticino experiences the highest overall average prices. This suggests that while the Ticino area seems to be well interlinked with Italy (thus high prices are imported from Italy) the east of Valais seems to lack sufficient transmission capacity to transport generated electricity away to neighbouring regions. The fact that prices actually go negative and do not stop at the zero lower bound is likely related to the large amount of exogenous hydropower in our model as we only model a subset of hydropower plants endogenously. This is going to change in future versions of the model as more hydropower plants are included.

The price picture, however, gives a first impression on where in the system bottlenecks could be expected and which regions would be likely to face higher and lower prices respectively if Switzerland were to switch to a nodal or zonal pricing system.

\section{Conclusion}

Swissmod captures the building blocks of the Swiss electricity market covering both the basic electricity characteristics and hydrological fundamentals, especially with respect to the hydrologic coupling between hydropower plants. The model is calibrated for 2012 and is able to reproduce both the Swiss as well as its neighbouring countries' supply and demand pattern.

The basic model can be extended to simulate the impact of future energy policies, capture the interactions of the different system components and provide estimates for the impact on the Central European electricity markets. Especially the hydropower system of Switzerland is expected to play a major role in stabilizing the European electricity system when high shares of intermittent RES generation are commonplace. The degree of detail in the model makes it possible to analyze how the usage patterns of hydropower is changing with different market conditions and their impact on overall market outcomes both in a spatial and time 
dimension. Therefore, combining a DC electricity load-flow model with a model of the hydraulic system is likely to yield important conclusions for Switzerland and its neighboring countries and can be applied similarly to other countries with a large share of hydropower.

\section{References}

Babonneau, Frédéric, Alain Haurie, Guillaume Jean Tarel, and Julien Thénié (2012). "Assessing the future of renewable and smart grid technologies in regional energy systems." eng. In: Swiss journal of economics and statistics 148 (2), pp. 229-273.

BAFA (2014). Drittlandskohlepreis. German Federal Office of Economics and Export Control. URL: http : //www . bafa.de/bafa/de/energie/steinkohle/drittlandskohlepreis/ (visited on 03/15/2014).

BAFU (2012). Einzugsgebietsgliederung Schweiz EZGG-CH. Swiss Federal Office for the Environment. URL: http://www. bafu.admin.ch/ezgg-ch.

Balmer, Markus, Dominik Möst, and Daniel Spreng, eds. (2006). Schweizer Wasserkraftwerke im Wettbewerb. Eine Analyse im Rahmen des europäischen Elektrizitätsversorgungssystems. ger. Wirtschaft, Energie, Umwelt. Zürich: vdf Hochsch.-Verl. an der ETH. 208 pp. ISBN: 9783728130488.

BFE (2011). Kurzbericht Netze. Swiss Federal Office of Energy. URL: http://www . bfe . admin . ch / php / modules / publikationen / stream . php ? extlang = de \\&name = de $\backslash$ _840756874.pdf (visited on 03/28/2013).

- (2012a). Erläuternder Bericht zur Energiestrategie 2050. URL: http://www.bfe.admin. $\mathrm{ch} /$ themen / $00526 / 00527 /$ index . html ? lang=de \\&dossier \_id=05773 (visited on 03/15/2013).

- (2012b). Statistik der Wasserkraftanlagen (WASTA). Swiss Federal Office of Energy. URL: http://www.bfe.admin . ch/geoinformation/05061/05249/index.html?lang= de (visited on 03/29/2013).

- (2013). Schweizerische Elektrizitätsstatistik 2012. Swiss Federal Office of Energy.

Consentec (2012a). Auswirkungen eines verstärkten Ausbaus der dezentralen Erzeugung auf die Schweizer Verteilnetze. Bern.

- (2012b). Einfluss verschiedener Stromangebotsvarianten auf das Übertragungsnetz der Schweiz. Bern.

Ecoplan (2012). Energiestrategie 2050. volkswirtschaftliche Auswirkungen. URL: http:// WwW . bfe .admin. ch/php/modules/publikationen/stream . php? extlang=de \\&name= de \_273048255.pdf.

Egerer, Jonas, Clemens Gerbaulet, Richard Ihlenburg, Friedrich Kunz, Benjamin Reinhard, Christian von Hirschhausen, Alexander Weber, and Jens Weibezahn (2014). Electricity Sector Data for Policy-Relevant Modeling. Data Documentation and Applications to the German and European Electricity Markets. 
ENTSO-E (2013). Yearly Statistics \& Adequacy Retrospect 2012. Brussels: European Network of Transmission System Operators for Electricity.

Eurelectric (2013). Power Statistics \& Trends 2012. full report.

Fischer, Reinhard and Friedrich Kießling (1989). Freileitungen. Planung, Berechnung, Ausführung. 3rd ed. Berlin: Springer. 429 pp. ISBN: 038719262X.

Kannan, Ramachandran and Hal Turton (2012). "Cost of ad-hoc nuclear policy uncertainties in the evolution of the Swiss electricity system." In: Energy Policy 50, pp. 391-406. ISSN: 03014215. DOI: 10.1016/j .enpol.2012.07.035.

Leuthold, Florian U., Hannes Weigt, and Christian von Hirschhausen (2012). "A large scale spatial optimization model of the European electricity market." In: Networks and spatial economics : a journal of infrastructure modeling and computation 12 (1), pp. 75-107.

Marcucci, Adriana and Hal Turton (2012). "Swiss energy strategies under global climate change and nuclear policy uncertainty." eng. In: Swiss journal of economics and statistics 148 (2), pp. 317-345.

Mathys, Nicole A., Philippe Thalmann, and Marc Vielle (2012). "Modelling contributions to the Swiss energy and environmental challenge. Special issue on energy modelling: introductory article." eng. In: Swiss journal of economics and statistics 148 (2), pp. 97109.

Prognos AG (2012). Die Energieperspektiven für die Schweiz bis 2050. Energienachfrage und Elektrizitätsangebot in der Schweiz 2000 - 2050. URL: http://www.bfe.admin.ch/php/ modules/publikationen/stream .php?extlang=de \\&name=de \_564869151.pdf.

Schweppe, Fred C., Michael C. Caramanis, Richard D. Tabors, and Roger E. Bohn (1988). Spot pricing of electricity. The Kluwer international series in engineering and computer science. Power electronics and power systems. by Fred C. Schweppe, Michael C. Caramanis... [et al.] Boston: Kluwer Academic. ISBN: 0-89838-260-2.

Stigler, Heinz and Christian Todem (2005). "Optimization of the Austrian Electricity Sector (Control Zone of VERBUND APG) under the Constraints of Network Capacities by Nodal Pricing." In: European Journal of Operations Research (13), pp. 105-125.

Swissgrid (2012). Energiewende. Übertragungsnetz mit Schlüsselrolle. URL: http : //www . swissgrid.ch/dam/swissgrid/company/publications/de/Energiewende】_de.pdf.

- (2013). Netzdaten 2012.

Weidmann, Nicolas, Ramachandran Kannan, and Hal Turton (2012). "Swiss climate change and nuclear policy. A comparative analysis using an energy system approach and a sectoral electricity model." eng. In: Swiss journal of economics and statistics 148 (2), pp. 275-316. 


\section{Appendix I: Demand regression results}

\begin{tabular}{|c|c|c|}
\hline & load & t-statistics \\
\hline$n v l$ & $1.588^{* * *}$ & 55.39 \\
\hline$y_{2011}$ & 0 & . \\
\hline$y_{2012}$ & $452.7^{* * *}$ & 11.97 \\
\hline$y_{2013}$ & $773.5^{* * *}$ & 18.52 \\
\hline$m_{1}$ & 0 & . \\
\hline$m_{2}$ & $-292.2^{* * *}$ & -3.92 \\
\hline$m_{3}$ & -130.5 & -1.73 \\
\hline$m_{4}$ & $823.2^{* * *}$ & 9.45 \\
\hline$m_{5}$ & $1348.2^{* * *}$ & 14.28 \\
\hline$m_{6}$ & $1266.4^{* * *}$ & 13.61 \\
\hline$m_{7}$ & $1642.6^{* * *}$ & 16.09 \\
\hline$m_{8}$ & $715.3^{* * *}$ & 7.81 \\
\hline$m_{9}$ & $911.0^{* * *}$ & 10.26 \\
\hline$m_{10}$ & $1048.0^{* * *}$ & 12.17 \\
\hline$m_{11}$ & $176.4^{*}$ & 2.08 \\
\hline$m_{12}$ & $386.2^{* * *}$ & 4.58 \\
\hline _cons & $-2290.3^{* * *}$ & -10.74 \\
\hline$N$ & 810 & \\
\hline
\end{tabular}

Table 3: Demand regression results 


\section{Appendix II: Hydro system graph}

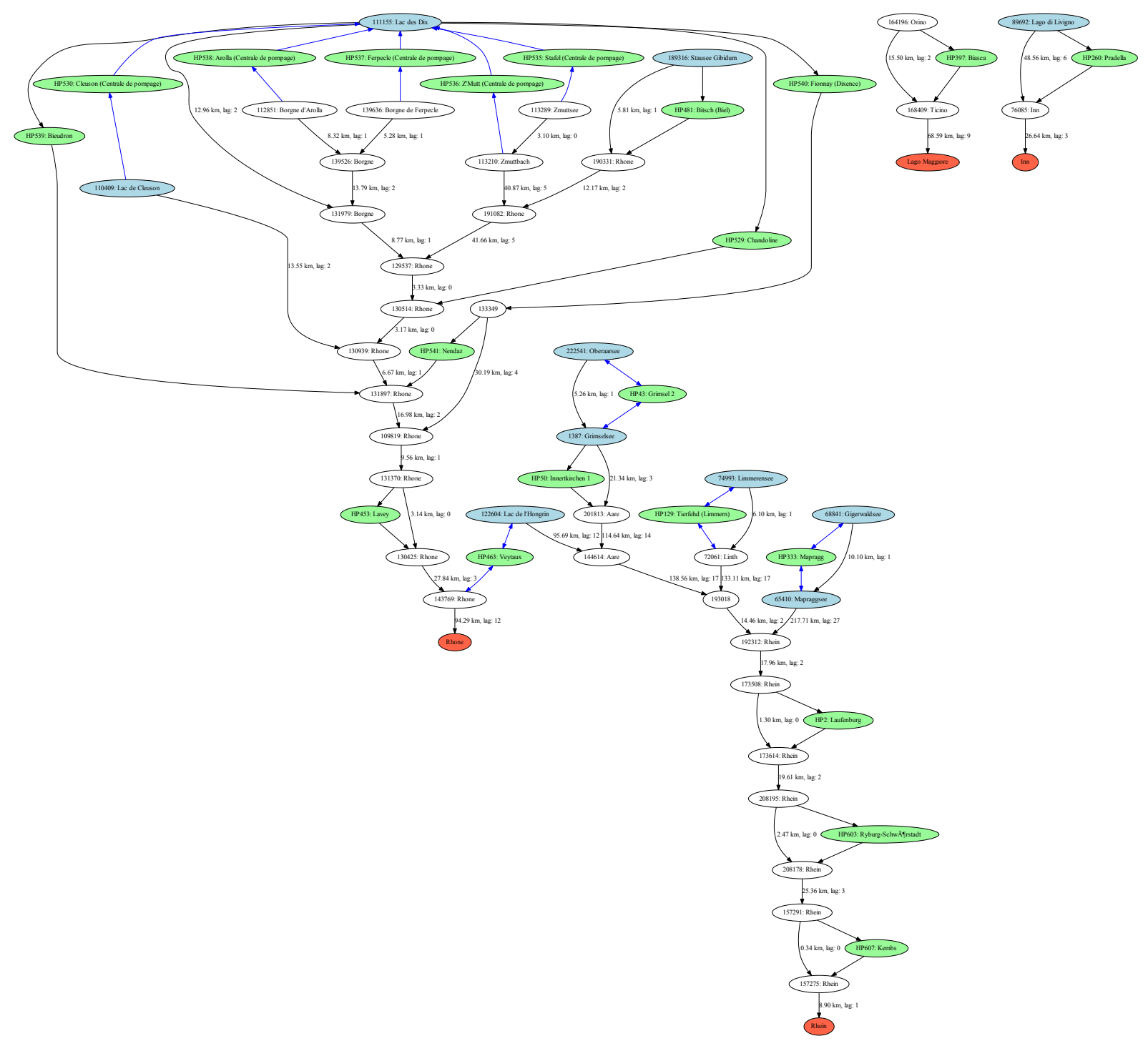

Figure 8: Hydro system graph 